Cardiol Young 1995; 5: 293-301

(C) World Publishers Limited ISSN 1047-9511

\title{
Editorial
}

\section{Rheumatic fever-T. Duckett Jones and the rest of the story}

\author{
L. George Veasy \\ From the Division of Cardiology, Department of Pediatrics, The University of Utah School of Medicine and \\ Primary Children's Medical Center, Salt Lake City
}

Key words: Rheumatic fever; rheumatic heart disease; mitral regurgitation; aortic regurgitation; Group A streptococcal infection

$\mathrm{D}$ R. T. DUCKETT JONES' ADDRESS TO THE SECTION on Pediatrics at the 1944 Annual Meeting of the American Medical Association in Chicago was first published in the Journal of the American Medical Association in October 1944. ${ }^{1}$ The fiftieth anniversary of this significant contribution passed essentially unnoticed.

This landmark address, entitled The Diagnosis of Rheumatic Fever, described major and minor manifestations of rheumatic fever which became known as Jones Criteria. His proposal that the presence of two major or one major and two minor manifestations would make the diagnosis of rheumatic fever quite probable has served as the standard to establish the diagnosis of rheumatic fever throughout the world. Although the initial criteria proposed by Jones have been altered no less than four times, the basic concepts he proposed remain intact. Under the sponsorship of the American Heart Association these changes and the years in which they have been published are as follows: Modified (1955), ${ }^{2}$ Revised (1965 and 1984), ${ }^{3,4}$ and Updated (1992). ${ }^{5}$

The latest of the official American Heart Associarion publications, Guidelines for the Diagnosis of Rheumatic Fever: The Jones Criteria, Updated $1992,{ }^{5}$ was drafted to emphasize the diagnosis of the initial attack of rheumatic fever (Table 1). A critical review of the discussion of the "updated" major and minor manifestations reveals, in the author's opinion, several inaccuracies. The purpose of this publication is three-fold: 1) to review the evolution of the Jones Criteria to explain how misinterpretations may have occurred; 2) to suggest further

Correspondence to Dr. L. George Veasy, Department of Pediatrics, The University of Utah School of Medicine, 50 North Medical Drive, Salt Lake City, Utah 84132, USA.

Accepted for publication 01 May 1995 modifications of Jones Criteria to comply more accurately with our current understanding of the disease; and 3) to relate some interesting but infrequently referenced historical events (the rest of the story).

\section{Critique of Jones Criteria, Updated 1992-Major Manifestations}

Carditis

Carditis has always been the first and most important element to be considered in establishing a diagnosis of rheumatic fever since it may result in the only signifcant sequela of this disease. ${ }^{6,7}$ It is the sole cause for childhood fatality during an early episode of rheumatic fever and later in adult life when rheumatic activity is not evident but rheumatic heart disease becomes apparent. The confirmation of carditis during the initial attack of rheumatic fever depends solely upon the auscultatory recognition of mitral and/or aortic valvar incompetence. Echocardiographic demonstration of valvar incompetence should be limited to special circumstances to be described later.

\section{Apical systolic murmur-mitral regurgitation}

The murmur of mitral regurgitation resulting from rheumatic fever is heard throughout systole and appropriately should be called a "regurgitant" murmur to differentiate it from a systolic "ejection" murmur caused by relative or absolute ventricular outflow obstruction ${ }^{8}$ (Figure). The murmur of mitral regurgitation has a high frequency because of the large systolic pressure gradient between the left ventricle and the left atrium during systole ( $>100 \mathrm{~mm} \mathrm{Hg}$ ). Regurgitant flow is present at the time of mitral valve closure and consequently the murmur usually begins with the first heart sound. A pressure gradient between the left ventricle and the left atrium persists after aortic closure so that the murmur 
Table 1. Guidelines for the diagnosis of initial attack of rheumatic fever (Jones Criteria, 1992 Update) $^{*}$

Major manifestations ${ }^{\dagger}$
Carditis
Polyarthritis
Chorea
Erythema marginatum
Subcutaneous nodules
Minor manifestations ${ }^{\dagger}$
Clinical findings
Arthralgia
Fever
Laboratory findings
Elevated acute phase reactants
Erythrocyte sedimentation rate
C-reactive protein
Prolonged PR interval

Supporting evidence for antecedent group A streptococcal infections $s^{\S}$

Positive throat culture or rapid streptococcal antigen test

Elevated or rising streptococcal antibody titer

*If supported by evidence of preceding group A streptococcal infection, the presence of two major manifestations or of one major and two minor manifestations indicates a high probability of acure rheumatic fever. 'See

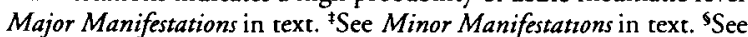
Supporting evidence for antecedent group $A$ streptococcal infection in text. (Reproduced with permission from J Am Med Assoc 1992; 268: 20692073. ${ }^{\circ}$ American Medical Associarion) can be detected slightly beyond the second sound. ${ }^{910}$ The murmur has a slight but definite accentuation as the left ventricular-to-left atrial gradient reaches its maximum in mid systole. ${ }^{10}$ The murmur is heard at the apex and extends toward the axilla because it is the left ventricle which transmits the vibratory activity generated by the turbulent regurgitant flow to the chest wall.

Dr. Jones originally described the murmur of mitral regurgitation as "a loud, long, apical systolic murmur widely heard and not varying with position." This original description and all published alterations of Jones criteria, including the 1992 Update, have emphasized that the murmur of mitral regurgitation is not altered by changes in position or phases of respiration. This indeed is true when the murmur is loud (Grade 3). However, when the murmur is soft (Grade 2 or less), the murmur unequivocally can be more readily detected when the patient assumes a left lateral decubitus position with forced expiration, " allowing the left ventricle to be closer to the chest wall. A murmur caused by minimal mitral regurgitation may only be detected by such a maneuver.

The emphasis on the lack of change with position may be, in part, attributed to the fact that the classical Still's, or innocent vibratory murmur, is more prominent when the patient is supine and decreases in intensity or disappears completely with sitting or standing. ${ }^{12}$

\begin{tabular}{|c|c|c|c|}
\hline DIAGNOSIS & MURMUR & SITE & SECOND SOUNO \\
\hline $\begin{array}{l}\text { Rheumatic mitral } \\
\text { regurgitation, muld }\end{array}$ & 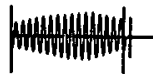 & $\begin{array}{l}\text { Apex } \\
\text { Better with patient } \\
\text { left decubitus }\end{array}$ & Normal \\
\hline $\begin{array}{l}\text { Rheumatic mitral } \\
\text { regurgitation, } \\
\text { moderate to marked }\end{array}$ & humunn!u & $\begin{array}{l}\text { Apox, } \\
\text { both systolic and } \\
\text { earty-mid diastolic }\end{array}$ & Slightly widened \\
\hline $\begin{array}{l}\text { Barlow Syndrome } \\
\text { (mitral prolapse) } \\
\text { billowing mitral leafiet, } \\
\text { click-murmur syndrome }\end{array}$ & & Apex & Normal \\
\hline $\begin{array}{l}\text { Obstructive cardiomyopathy } \\
\text { (IHSS) }\end{array}$ & & Apex & $\begin{array}{l}\text { Narrow split } \\
\text { or reversed }\end{array}$ \\
\hline $\begin{array}{l}\text { Ventricular septal defect. } \\
\text { small }\end{array}$ & huntunty & Left stemal $\theta$ dge & Normal split \\
\hline $\begin{array}{l}\text { Ventricular septal delect, } \\
\text { moderate }\end{array}$ & 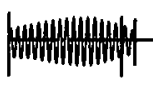 & $\begin{array}{l}\text { Leth stemal edge } \\
\text { (Diastolic flow murmur } \\
\text { at apex) }\end{array}$ & $\begin{array}{l}\text { Wide split } \\
\text { P2 accentuated }\end{array}$ \\
\hline Valvular aortic stenosis & & $\begin{array}{l}\text { Upper right stemal edge } \\
\text { Ejection "click" at apex }\end{array}$ & $\begin{array}{l}\text { Narrow split } \\
\text { (reversed if severe) }\end{array}$ \\
\hline $\begin{array}{l}\text { Innocent murmurs } \\
\text { Still's (vibratory) }\end{array}$ & & Lower left stemal edge & Normal \\
\hline Pulmonary flow & & $\begin{array}{l}\text { Upper left stemal edge } \\
\text { (with fover, anemia) }\end{array}$ & Normal \\
\hline
\end{tabular}

Figure. Distinguishing characteristics of systolic murmurs. 
Still's murmur, however, should be differentiated from the murmur of mitral regurgitation by its lower frequency and its being an ejection murmur rather than a regurgitant murmur (Figure 1).

\section{Apical mid-diastolic murmur}

In the 1992 Update two separate mid-diastolic murmurs are described. The first is associated with marked mitral regurgitation. The additional volume of blood in the left atrium contributed by the regurgitant flow results in an increased flow through the mitral valve during early-mid diastole when ventricular filling is most rapid. This murmur was originally described in 1924 by Dr. Carey Coombs of Bristol, England..$^{13}$ In his description of the murmur, he found it to be present only in young individuals and noted it was always associated with a "systolic bruit." This murmur is now well known as the Carey Coombs murmur, which often is incorrectly hyphenated (Carey-Coombs). This murmur is heard only in the presence of mitral regurgitation and is low pitched, since the turbulence is caused by the increased "flow" without a pressure gradient. The vibratory activity is again transmitted by the left ventricle to the chest wall and is thereby heard best in the apical area. This same "flow" murmur can be heard with increased flow across the mitral valve from the left-to-right shunt caused by a large ventricular septal defect.

A second mid-diastolic murmur is described for the first time in the 1992 Update. In the discussion of the modified and revised Jones criteria, the Carey Coombs murmur was described separately but always appropriately associated the murmur with mitral regurgitation. This second isolated mid-diastolic murmur ascribed to be specific in the 1992 Update is not and could not be present with the initial attack of rheumatic fever. An isolated mid-diastolic murmur conceivably could be caused by rheumatic mitral valve disease in the absence of mitral regurgitation if the mitral leaflets had become fused to prohibit flow in early-mid diastole during the time of rapid ventricular filling. This would be the earliest manifestation of mitral stenosis but never would be present as an isolated finding with the initial attack of rheumatic carditis.

Since a mid-diastolic murmur had been described separately in Jones Criteria ${ }^{2-4}$ and other publications, ${ }^{8,14,15}$ without stressing its absolute association with mitral regurgitation, it was inappropriately assumed by some that an isolated mid-diastolic murmur was the "Carey-Coombs" murmur. In the author's opinion, this misinterpretation would never have been made by anyone who had read Dr. Coombs' classical description of the murmur.

\section{Basal diastolic murmur-aortic regurgitation}

The description of the murmur of aortic regurgitation in the 1992 Update is exceptionally well written and deserves only commendation. As described it can be heard best with the patient leaning forward, bringing the heart closer to the anterior chest wall. Because of its relatively high frequency, the murmur may not be detected without careful auscultation. It should be appreciated that the murmur has a higher frequency and is more intense at the beginning of diastole when the gradient between the aorta and the left ventricle is greatest. The murmur decreases in frequency and in intensity when the pressure gradient decreases as diastolic pressure falls. Hence, the decrescendo quality of the murmur.

\section{Myocarditis}

It should be stressed that myocarditis in the absence of valvulitis (mitral and/or aortic regurgitation) is never rheumatic in origin. ${ }^{16}$ Myocardial involvement in acute rheumatic carditis unequivocally does exist, but it is not significant from a clinical standpoint except for its probable role in mitral annulus dilatation. ${ }^{17}$ In the rare patient who develops congestive failure with the initial attack or early recurrence, restoration of valvar competence results in immediate and dramatic improvement. ${ }^{17-20}$ While a prolongation of the P-R interval suggests myocarditis, the finding is not specific. Clinically there is no way to establish the presence of myocarditis. Even myocardial biopsy, an unnecessary diagnostic procedure, will not consistently confirm the presence of myocardial involvement in the presence of clinically established active carditis. ${ }^{21}$

\section{Pericarditis}

Pericarditis, as with myocarditis, in acute rheumatic fever is never encountered in the absence of valvar involvement. The precordial pain of pericarditis automatically directs attention to the heart, but from a practical standpoint is not hemodynamically significant. With pericardial effusion the heart sounds become more distant and a friction rub could over-ride the murmur of mitral and/or aortic regurgitation. Since the presence of pericarditis is routinely confirmed by echocardiography, when mitral regurgitation cannot be detected by auscultation its presence or absence should be determined by Doppler interrogation (to be discussed later). Rheumatic pericarditis rarely results in tamponade.

The presence of pericarditis, particularly with a markedly erythematous and painfully swollen joint, should be considered to have an infectious etiology rather than rheumatic until proven otherwise. While cautious observation of rheumatic pericarditis is appropriate, the presence of purulent pericarditis demands immediate confirmation by pericardial tap and both antibiotic and surgical intervention. 


\section{Role of echocardiography}

Echocardiography is the only new diagnostic tool to be introduced in the past two decades which significantly contributes to establishing the diagnosis of rheumatic fever by confirming the presence of rheumatic carditis (mitral regurgitation). Presently, echocardiography is most commonly used to differentiate the murmur of mitral regurgitation from systolic murmurs caused by ventricular septal defects, obstructive cardiomyopathy, and the click-murmur syndrome associated with mitral valve prolapse (Barlow's syndrome). These lesions should be readily differentiated from mitral regurgitation by auscultation alone (Figure 1). However, today's trainees (and even some less confident experienced clinicians) may feel more comfortable with echocardiographic confirmation rather than relying on limited auscultatory skills.

Echocardiography has increased our knowledge of the parhogenesis of acure rheumatic mitral regurgitation. Rather than leaflet edema, chordal contraction and leaflet deformity, we now know that mitral regurgitation results from annular dilatation and secondary chordal elongation which permits the apical portion of the anterior leaflet to prolapse back into the left atrium. ${ }^{17,22}$ This causes a characteristic jet of regurgitant flow that passes over the posterior leaflet striking the posterior left atrial wall in the area that MacCallum's patch is known to be present. Chordal elongation can become so severe that the anterior mitral leaflet can actually become flail. This usually doesn't occur with the initial attack of rheumatic fever but can be seen in a subsequent attack, particularly if it occurs shortly after the initial attack. ${ }^{17}$

Recent experience ${ }^{23-25}$ suggests that "silent" mitral regurgitation can be demonstrated by Doppler evaluation in patients presenting with "pure" chorea and isolated rheumatic polyarthritis. On the other hand, studies employing Doppler evaluation of valvar function have demonstrated the presence of mitral regurgitation in individuals known to have normal hearts. ${ }^{26,27}$ Consequently, there is an understandable reluctance to accept only echocardiographic (Doppler) evidence of mitral regurgitation that is not audible. The special writing commitree appropriately expressed its concerns in the 1992 Update, that echocardiographic findings could be over interpreted and result in iatrogenic heart disease. Inappropriate application of this new technology unquestionably can result in over-diagnosis.

To avoid over-diagnosis, the demonstration of mitral regurgitation or aortic regurgitation that cannot be heard should be limited to those patients with equivocal confirmation of polyarthritis. Silent, but pathologic, mitral regurgitation can be differentiated from physiologic if the following rigid criteria are met: 1) Regur- gitant flow should be holosystolic. 2) The regurgitant flow should extend back to the left atrial wall. 3) The regurgitant flow should have definite aliasing (mosaic pattern on color flow). 4) The regurgitant flow should be confirmed in more than one plane. Silent aortic regurgitation can be confirmed by the regurgitant jet being 1) holodiastolic and 2) extending into the left ventricle to the tip of the anterior mitral leaflet.

Echocardiography should prove to be particularly valuable in follow-up studies since we have available for the first time a non-invasive means of following the anatomic and hemodynamic changes that occur in chronic rheumatic heart disease from childhood through adult life.

\section{Polyarthritis}

Polyarthritis has always been the "Achilles' heel" of Jones criteria. The list of disorders which can mimic rheumatic polyarthritis is very long and includes most prominently juvenile rheumatoid arthritis, post viral arthritis, and systemic lupus. At the onset of polyarthritis, a given diagnosis is often difficult to establish. Continued cautious observation, however, invariably permits differentiation by clinical and laboratory assessment.

Rheumatic arthritis can present with a wide range of severity and duration. ${ }^{28,29}$ The pain can be so severe that the patient may refuse to walk and will scream with pain when barely touched, even by bed clothing. On the other hand, the pain may be so mild that it is often not readily recalled a week later. The pain can last less than 24 hours or recur on and off for weeks.

Rheumatic polyarthritis usually involves the larger joints of the body, that is, the knees, ankles, shoulders and hips. Characteristically, the pain far exceeds the objective findings which may well be the reason Dr. Jones originally chose polyarthralgia rather than polyarthritis as a major manifestation. The 1955 Modification, which Dr. Jones personally endorsed, and all subsequent changes in Jones criteria, have required only minimal objective findings to establish the presence of arthritis. Limitation of voluntary motion and tenderness to touch are acceptable and both are usually present.

Even though Feinstein and Spagnuolo described rheumatic joints as typically red, hot or swollen, ${ }^{30}$ this has not been the author's experience. Objective findings such as swelling and increased warmth, when present, are usually not marked even when they can be demonstrated. Redness is uncommon and when present with rheumatic arthritis usually only a small area of mild erythema is encountered. Any joint that is markedly inflamed and swollen should be considered septic. If this is associated with pericarditis, as previously mentioned, the first consideration should be that it is infectious, mandating immediate confirmation and 
intervention.

While the author has seen patients who have gained symptomatic relief of their pain using Ibuprofen and other non-steroidal anti-inflammatory agents, salicylates consistently provide the most effective relief. When patients fail to respond to aspirin on a dosage of $100 \mathrm{mg} /$ $\mathrm{kg} /$ day after 48 hours, a salicylate level should be taken to be certain a therapeutic range of $20-25 \mathrm{mg} / \mathrm{dl}$ has been obtained.

"Post-streptococcal reactive arthritis" has many ardent advocates ${ }^{31-33}$ claiming the syndrome is a new disease entity. In the author's opinion this syndrome is nothing more than good old-fashioned rheumatic fever. There is nothing to be gained by putting a wolf in sheep's clothing as though a new entity had suddenly appeared. Even the strongest advocates ${ }^{32.33}$ of this improperly identified syndrome suggest its management be identical to that of rheumatic fever, so why the new name?

\section{Chorea (Sydenham chorea)}

This diagnosis is usually missed when it is not considered. The involuntary, purposeless, non-repetitive movement characteristic of this disorder usually permits a rapid diagnosis. If the examiner is in doubt after eliciting a confirmatory "nervous" milking grip, a positive pronator sign, hanging knee jerk, etc., neurologic consultation should be obtained. There is litrle reason to initiate expensive imaging examinations (MRI and CT scan) if the findings are typical. The presence of mitral regurgitation, of course, is absolutely confirmatory.

\section{Erythema marginatum and subcutaneous nodules}

These two skin manifestations should be discussed together since they rarely are seen without an accompanying major manifestation. For all practical purposes, erythema marginatum is seen only when carditis and/or arthritis are also present. Erythema marginatum in the presence of polyarthritis, of course, would confirm the diagnosis of rheumatic fever even in the absence of carditis. On the other hand, subcutaneous nodules are rarely encountered when carditis is not also present. The skin manifestations by themselves essentially never establish the diagnosis of rheumatic fever.

\section{Critique of Jones Criteria, Updated 1992-Minor Manifestations}

\section{Clinical}

FEVER

Fever is usually present during the first week to ten days of rheumatic fever but is rarely above $39^{\circ} \mathrm{C}$. If the patient's temperature elevation persistently exceeds 39 ${ }^{\circ} \mathrm{C}$, other causes for the patient's fever should be sought. In particular, in the presence of rheumatic heart disease, superimposed infective endocarditis should be a first consideration.

\section{ARTHRALGIA}

Arthralgia, of course, cannot be used as a minor criterion in the presence of arthritis. One should be certain, however that the pain involves the joint and not the periarticular or muscular tissues.

\section{Laboratory findings}

\section{ELEVATED ACUTE PHASE REACTANTS}

Any patient with active rheumatic polyarthritis or with overtly active carditis will have an elevated sedimentation rate which typically is very marked. A C-reactive protein, likewise, is universally elevated. During the acute illness, a normal sedimentation rate and C-reactive protein level strongly suggest a non-rheumatic etiology. There are two clinical situations in which acute phase reactants may be normal and yet are clearly rheumatic in etiology. These are discussed later as "Exceptions."

\section{PROLONGED PR INTERVAL}

A prolonged $\mathrm{PR}$ interval on the electrocardiogram is nonspecific but can be encountered during the acute attack of rheumatic fever $(25-40 \%) \cdot{ }^{34} \mathrm{Dr}$. Jones, in 1944 , recommended tracings be repeated to demonstrate a variation in atrioventricular conduction. This recommendation has not been mentioned in subsequent changes. The author believes that repeat tracings can be valuable when changing atrioventricular conduction is demonstrated. A prolonged PR interval of $0.20 \mathrm{sec}$ that persists may not have the same significance as a PR interval of $0.15 \mathrm{sec}$ with a heart rate of 120 that decreases to $0.12 \mathrm{sec}$ with a rate of 100 .

\section{Supporting evidence for antecedent group $A$ streptococcal infection}

It is universally accepted that rheumatic fever follows a Group A streptococcal infection and, specifically, a streptococcal pharyngitis. During epidemic years of streprococcal pharyngitis the incidence can be as high as three percent of untreated patients. ${ }^{35}$ During non-epidemic years the incidence can be so low as to be considered non-existent.

It is logical to believe that the best way to confirm an antecedent infection is with a positive throat culture for Group A streptococci. Actually, this is often not the case. The patient characteristically has recovered from the streptococcal pharyngitis by the time he develops rheumatic fever and the recovery rate of Group A streptococci by throat culture from patients with confirmed rheumatic fever is only about $25 \%$. $^{5}$ Throat cultures done routinely on school children may be positive in $10-40 \%$ of the asymptomatic children dur- 
ing the winter and spring months. ${ }^{6}$ Moreover, a signifcant number of these children may be carriers of group A streptococci.

Throat cultures in hospital or clinic settings are usually performed by laboratory technicians or nurses, often somewhat gingerly, which may be responsible in part for the low recovery rate. Throat cultures should be done routinely on every suspected case of rheumatic fever and repeated in 24 hours if negative. Freezing a positive culture from an index case of rheumatic fever is not routine, but should be considered for possible follow up epidemiological and investigative studies. In the event of a negative culture from the index case, cultures of siblings may yield the most likely offending organism.

Streptococcal antibody titers should be determined routinely since they are more sensitive and reliable in establishing an antecedent streptococcal infection. When low they should be repeated a week to two weeks after the initial assessment (if rheumatic fever is still suspected clinically) to see if the titers are rising or falling. ${ }^{4}$ There are two antibody determinations that are used most commonly. The antistreptolysin O-titer has been used since Dr. Jones' time, and during the last 20 years anti-DNAse $B$ has been the next most frequently used antibody determination. Using the combined determinations increases the confirmation in rheumatic fever from $80 \%$ with an antistreptolysin O-titer titer to $92 \%$ with the two determinations. ${ }^{37}$ It is important that titers be compared to established community and age-matched normal values. ${ }^{5}$

\section{Over-diagnosis of rheumatic fever}

Dr. Jones' proposal to make diagnosing rheumatic fever more accurate was made primarily to enable accumulation of reliable epidemiologic data and secondarily to prevent the then common error of over-diagnosing rheumatic fever.

In his original 1944 presentation, Dr. Jones emphasized that a long period of observation is often necessary before a diagnosis can be established. It is quite correct to delay treatment until one can clearly establish or rule out the presence of active rheumatic fever. The one caveat involves a situation in which a septic joint is a possibility which requires early diagnosis and intervention.

\section{Exceptions}

Two exceptions to the Jones criteria were mentioned in the 1965 Revised guidelines and appropriately stressed in the 1992 Updated guidelines. Either of these exceptions occurring as isolated manifestations establish rheumatic etiology without accompanying major or minor manifestations. The first exception is the appearance of a new murmur of mitral or aortic regurgitation with no evidence of rheumatic activity otherwise, that is, the patient is asymptomatic, afebrile, and has a normal sedimentation rate. The 1992 Update uses the term "indolent carditis" for previously unrecognized rheumatic heart disease not associated with a past episode of rheumatic fever. There is no way one can predict whether newly discovered rheumatic valvar deformity will progress, remain the same, or improve. Only time will tell if slow progressive inflammatory changes will occur as the term "indolent" tends to imply. The term rheumatic heart disease with the appropriate hemodynamic alteration-that is, mitral regurgitation, aortic regurgitation--should be used.

The second exception is the appearance of Sydenham chorea, which should always be considered rheumatic unless the presentation is atypical. In both typical and atypical cases, careful auscultation for mitral regurgitation should be completed.

\section{Jones Criteria-focused}

Without a specific confirmatory laboratory test, which does not appear imminent, Jones criteria remain the only means to establish the diagnosis of rheumatic fever. In a disease with such protean manifestations, establishing a set of specific diagnostic criteria for use in all circumstances is a difficult, if not impossible, task. Jones' criteria basically were to be, and have always been, used in situations in which young individuals were acutely ill.

During the initial attack of rheumatic fever, the presence of rheumatic heart disease, that is, mitral/ aortic regurgitation, establishes the diagnosis. Supportive minor manifestations and confirmatory evidence of an antecedent streptococcal infection are essentially always present to satisfy Jones' criteria. In the presence of rheumatic heart disease, minor criteria contribute more to assessing the acuity of rheumatic activity than to establishing the diagnosis.

It is perhaps a misnomer to state patients with Sydenham chorea are not acutely ill since they may be totally incapacitated by the movement disorder. Even when chorea is most acute, these patients are afebrile and characteristically have no confirmatory clinical or laboratory minor manifestations. Since rheumatic heart disease and chorea singularly establish rheumatic etiology, the three remaining minor manifestations, polyarthritis, erythema marginatum and subcutaneous nodules, are the only manifestations requiring conventional confirmation by Jones criteria. As discussed, erythema marginatum is encountered essentially only in the presence of carditis and/or polyarthritis and subcutaneous nodules are seen with rare exception only when carditis is clearly evident. Thus, for all practical purpose, polyarthritis is the only major manifestation requiring confirmation by Jones criteria. 
It is a paradox that the most frequently encountered manifestation of this disease, which is responsible for its name, is also the least specific. Rheumatic polyarthritis can be extremely variable, both as to intensity and time, and confirmatory evidence of a preceding streptococcal infection can be equivocal. There now appears to be enough experience to add echocardiographic demonstration of silent valvar regurgitation as an additional minor manifestation ${ }^{23,25}$ (Table 2). Two groups believe Doppler evidence for valvar regurgitation should be accepted as carditis. ${ }^{23,25}$ Until more experience has been acquired, we are suggesting Doppler study for diagnostic purpose be limited to patients with isolated polyarthritis in whom the suspected diagnosis of rheumatic fever has equivocal confirmation by minor criteria.

To avoid the over-diagnosis of carditis rigid echocardiographic (Doppler) criteria must be employed. For mitral regurgitation, the regurgitant jet should be 1) holosystolic, 2) followed back to the left atrial wall, 3) accompanied by a mosaic pattern (aliasing), and 4) seen in two planes. For aortic regurgitation the regurgitant jet should 1) be holodiastolic, 2) extend into the left ventricle to the tip of the anterior mitral leaflet. The suggested modifications of Jones criteria are outlined in Table 2.

\section{The rest of the story}

While pursuing an explanation for the misinterpretation of the mid-diastolic murmur cited in the 1992 Update, the author was fortunate to recover a copy of Dr. Carey Coomb's book, Rheumatic Heart Disease, ${ }^{13}$ which was published in 1924. In this monumental work he meticulously related his extensive experience spanning two decades. For reasons unknown, this truly remarkable treatise is infrequently (or incorrectly) referenced.

Dr. Coombs had served as a clinical clerk to Dr. W. B. Cheadle, whose Harvean lectures on the "various manifestations of the rheumatic state as exemplified in childhood and early life" ${ }^{38}$ provided the most complete "modern" (1889) English description of the disease, including the association with a preceding pharyngitis and familial predisposition.

Dr. Coombs, however, was even more profoundly influenced by another senior colleague, Dr. Frederick J. Poynton, who practiced in London at the Hospital for Sick Children Great Ormond Street. Dr. Poynton is best known for a study published with Dr. Alexander Paine in 1900 entitled, Etiology of Rheumatic Fever. ${ }^{39} \mathrm{In}$ this article he proposed that rheumatic fever was caused by a diplostreptococcus which entered the body by way of the tonsils. Dr. Poynton and Dr. Paine were able to recover this organism which "sometimes grew in pairs and sometimes in chains" from cardiac tissue and a subcutaneous node from young individuals who died
Table 2. Jones Criteria-Focused: suggested changes.

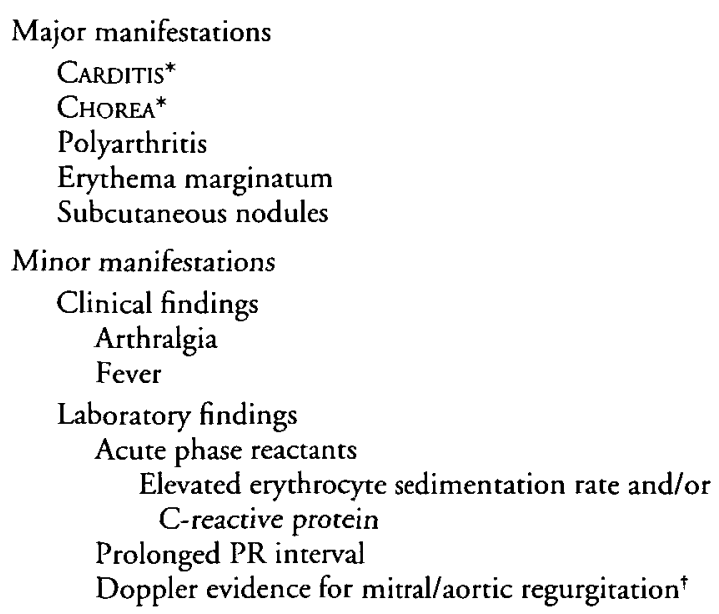

Supportive evidence for antecedent group A streptococcal infections

The following are changes from the 1992 Updated Jones Criteria: *CARDitis and ChOREA confirm rheumatic etiology as isolated major manifestations. ${ }^{\dagger}$ Doppler evidence of silent mitral or aortic regurgitation using rigid criteria in suspected rheumatic polyarthritis with equivocal confirmatory findings.

during an episode of acute rheumatic fever.

Dr. Coombs totally embraced the concept that rheumatic fever was an actual infection with the "streptococcus rheumaticus of Poynton." Both he and Dr. Poynton termed the infection "proliferative" but not "suppurative."

In the introductory paragraphs of the second chapter of his book, entitled Etiology, Dr. Coombs listed the four principal manifestations of the rheumatic infection. These were: 1) Carditis, 2) Polyarthritis, 3) Chorea, 4) Subcutaneous node. That these four principal manifestations precisely match the original Jones major criteria needs no comment.

The sixth chapter of his eleven chapter book was entitled Physical Signs. In this chapter he described four apical diastolic murmurs associated with mitral valve disease. The first was the classical murmur of mitral stenosis with presystolic accentuation.

The second apical diastolic murmur he described was the murmur of mitral stenosis that changed when "total arrhythmia" or "auricular" fibrillation appeared. The absence of the previously observed presystolic component was atrributed to "auricular" systole being ineffective.

The third murmur described by Dr. Coombs was the mid-diastolic murmur associated with mitral regurgitation. This murmur, which bears his name, was detected, as mentioned, only in the younger patient and was always associated with a "systolic bruit."

The fourth apical diastolic murmur was associated with aortic regurgitation and was acknowledged by Dr. Coombs as the Flint murmur, first described by Dr. Austin Flint, an American, in 1862. 
When Dr. Coombs examined the hearts of children who had succumbed during an acute attack of rheumatic fever associated with marked mitral regurgitation he was impressed with how little the mitral valve was deformed, which he felt could not explain the gross mitral valve incompetence that had been evident clinically. What he did note, however, was marked dilatation of the mitral "ring" which he attributed to myocardial injury from the active infection. In referring to these findings encountered only in childhood he stared, "At this time the cusps are but little deformed, but owing to the wide separation of the bases of the cusps by the stretching of the ring, the valvar apparatus is apparently rendered inadequate."

This concept was strengthened by Edwards and Burchell in $1958^{40}$ and has been further confirmed by echocardiographic studies in the last decade. ${ }^{17,22}$ These echocardiographic studies have shown, in addition to the annular dilatation, lengthening of the chordae of the anterior leaflet causing its apposing edge to prolapse back into the left atrium. This is turn can lead to severe mitral regurgitation with little associated deformity of the valve leaflets.

\section{Summary}

While we truly have gained significant insight into our understanding of the pathogenesis of rheumatic fever and rheumatic heart disease, we still find ourselves in an uncomfortable position not dissimilar to our predecessors. We still have no specific confirmatory test and continue to rely solely upon findings on physical examination to confirm the diagnosis. It is quite likely that we shall enter the twenty-first century without reaching Dr. T. Duckett Jones' ultimate goal of securing a foolproof means of diagnosing this most fascinating, yet perplexing, disease.

\section{References}

1. Jones, TD. The diagnosis of rheumatic fever. J Am Med Assoc 1944; 126: 481-484.

2. Rutstein DD, Bauer W, Dorfman A, Gross RE, Lichty JA, Taussig HB, Whittemore R, Hagberg K, Parker ME. Jones Criteria (Modified) for guidance in the diagnosis of rheumatic fever. Mod Concepts Cardiovasc Dis 1955; 24: 291-293.

3. Stollerman, GH, Markowitz M, Taranta A, Wannamaker LW, Whittemore R. Jones Criteria (Revised) for Guidance in the Diagnosis of Rheumatic Fever. American Heart Association Pamphlet EM 145, Dallas, 1965.

4. Jones Criteria (Revised) for guidance in the diagnosis of rheumatic fever. Circulation 1984; 69: 203A-208A.

5. Dajani AS, Ayoub E, Bierman Z, Bisno AL, Denny FW, Durack DT, Ferrieri P, Freed M, Gerber M, Kaplan EL, Karchmer AW, Markowitz, M, Rahimtoola SH, Shulman ST, Stotterman G, Takahashi M, Taranta A, Taubert KA, Wilson W. Guidelines for the diagnosis of rheumatic fever: Jones Criteria 1992 Update. J Am Med Assoc 1992; 268: 2069-
2073.

6. Markowitz M. Clinical manifestations of acute rheumatic fever. In: Markowitz M, Gordis L (eds). Rheumatic Fever. W.B. Saunders, Philadelphia, 1972, p 62.

7. Stollerman GH. Clinical manifestations of acute rheumatic fever. In: Stollerman GH. Rheumatic Fever and Streptococcal Infection. Grune and Stratton, New York, 1975, p 152.

8. Shaver JA, Leonard JJ, Leon DF. Heart murmurs. In: Examination of the Heart: Part 4. Auscultation of the Heart. American Heart Association, Dallas, 1990, pp 34-61.

9. Park MK. Valvular heart disease. In: Park K. Pediatric Cardiology for Practitioners. Year Book Medical Publishers, Inc., Chicago, 1988, pp 248-249.

10. Barlow JB, Pocock WA. Mitral and other systolic murmurs. In: Barlow JB. Perspectives on the Mirral Valve. F.A. Davis Company, Philadelphia, 1987, pp 135-138.

11. Leatham A. Systolic murmurs. In: Leatham A. Auscultation of the Heart and Phonocardiography. J. A. Churchill, London, 1970, pp 118-119.

12. Newberger JW. Innocent murmurs. In: Fyler D.C. (ed). Nadas' Pediatric Cardiology. Hanley and Belfus, Philadelphia, 1992, p 282.

13. Coombs CF. Physical signs. In: Coombs CF. Rheumatic Heart Disease. John Wright and Sons, Bristol, 1924, pp 190191.

14. Wood PH. Discussion on the management of rheumatic fever and its early complications: Cardiac complications. Proc Roy Soc Med 1950; 53: 195-209.

15. Nugent EW. Acute rheumatic fever. In: Hurst JW (ed). The Heart, Fourth Edition. McGraw-Hill, New York, 1970, p 983.

16. Fyler DC. Rheumatic fever. In: Fyler DC (ed). Nadas' Pediatric Cardiology. Hanley and Belfus, Philadelphia, 1992, p 313.

17. Barlow JB. Aspects of active rheumatic carditis. Aust NZ J Med 1992; 22: 592-600.

18. Lewis BS, Geft IL, Milo S, Gatsman MS. Echocardiography and valve replacement in the critically ill patient with acute rheumatic carditis. Ann Thoracic Surg 1979; 27: 529-35.

19. Duran DMG, Gometza B, DeVol EB. Valve repair in rheumatic mitral valve disease. Circulation 1991; 84(Suppl 3)III: 125-132.

20. Strauss AW, Goldring D, Kissane J, Hernandez A, Hartmann A, McKnight CR, Wildon CS. Valve replacement in acute rheumatic heart disease. J Thor Cardiovasc Surg. 1974; 67: 659-670.

21. Narula J, Chopra P, Talwar KK, Reddy S, Vasan RS, Tandon $R$, Bhatia M, Southern JF. Does endomyocardial biopsy aid in the diagnosis of active rheumatic carditis? Circulation. 1993; 88[Part 1]: 2198-2205.

22. Marcus RH, Sareli P, Pocock WA, Meyer TE, Magalhaes MP, Grieve T, Antunes MJ, Barlow JB. Functional anatomy of severe mitral regurgitation in active rheumatic cardiris. Am J Cardiol 1989; 63: 577-585.

23. Folger GM, Hajar R, Robida A, Hajar HA. Occurrence of valvar heart disease in acute rheumatic fever without evidence of carditis; colour flow Doppler identification. Br Heart J 1992; 67: 434-438.

24. Veasy LG, Tani LY, Hill HR. Persistence of acute rheumatic fever in the intermountain area of the United States. J Pediatr 1994; 124: 9-16.

25. Abernethy M, Bass N, Sharpe N, Grant C, Neutze J, Clarkson P, Greaves S, Lennon D, Snow S, Whalley G. Doppler echocardiography and the early diagnosis of carditis in acute rheumatic fever. Aust NZ J Med 1994; 24: 530-535.

26. Yosheda K, Yoshikawa J, Shakudo M, Akasak T, Jyo T, Takao S, Shiratori K, Korzumi K, Okumachi F, Kato H, Fukaya T. Color Doppler evaluation of valvular regurgitation in normals. 
Circulation 1988; 78: 840-847

27. Sahn DJ, Marciel BC. Physiologic valvular regurgitation: Doppler echocardiography and the potential for iatrogenic heart disease. Circulation 1988; 78: 1075-1077.

28. Markowitz M. Clinical manifestations of acute rheumatic fever. In: Markowitz M, Gordis L (eds). Rheumatic Fever. Lippincott, Philadelphia, 1989, p 70.

29. Stollerman GH. Clinical manifestations of acute rheumatic fever. In: Stollerman GH. Rheumatic fever and Streptococcal Infection. Grune and Stratton, New York, 1975, p 150.

30. Feinstein AR, Spagnuolo M. The clinical patterns of acute rheumatic fever: a reappraisal. Medicine 1962; 41: 279-305.

31. Arnold $\mathrm{MH}$, Tyndall A. Poststreprococcal reactive arthritis. Ann Rheum Dis 1989; 48: 686-688.

32. Gibbas DL, Broussard DA. Post streptococcal reactive polyarthritis (PSRA) - rheumatic fever or not? Arthritis Rheum 1986; 29: 92S.

33. DeCunto CL, Giannini EH, Fink, CW, Brewer EJ, Person DA. Prognosis of children with poststreptococcal reactive arthritis. Pediarr Inf Dis J. 1988; 7: 583-586.
34. Markowitz M. Radiographic and electrocardiographic findings. In: Markowitz M, Gordis L (eds). Rheumatic Fever. W.B. Saunders, Philadelphia, 1972, p 62.

35. Stollerman GH. Clinical manifestations of acute rheumatic fever. In: Stollerman GH. Rheumatic Fever and Streptococcal Infection. Grune and Stratton, New York, 1975, p 69.

36. Moffett HL. Nose and throat syndromes. In: Moffett HL. Pediatric Infectious Diseases. Lippincott, Philadelphia, 1989, p 24.

37. Ayoub EM. Acute rheumatic fever. In: Adams FH, Emmanoulides GC, Reimenschneider TA (eds). Moss' Heart Disease in Infants, Children and Adolescents, Fourth Edition. Williams and Wilkins, Baltimore, 1989, p 699.

38. Cheadle WB. Harvean Lectures on the various manifestations of the rheumatic state as exemplified in childhood and early life. Lancet 1889; 1: 821-827, 871-877, 921-927.

39. Poynton FJ, Paine A. The etiology of rheumatic fever. Lance 1900; 2: 861-869.

40. Edwards JE, Burchell HB. Pathologic anatomy of mitral insufficiency. Proc. Mayo Clin 1958; 33: 497-509. 